\title{
ERp29 induces breast cancer cell growth arrest and survival through modulation of activation of p38 and upregulation of ER stress protein $\mathrm{p} 58^{\mathrm{IPK}}$
}

\author{
Danmei Gao1, I Fon Bambang ${ }^{1}$, Thomas C Putti ${ }^{1}$, Yuan Kun Lee ${ }^{2}$, Des R Richardson ${ }^{3}$ and Daohai Zhang ${ }^{1,3}$
}

Endoplasmic reticulum protein 29 (ERp29) is an ER luminal protein that has a role in protein unfolding and secretion, but its role in cancer is unclear. Recently, we reported that overexpression of ERp29 significantly inhibited cell proliferation and prevented tumorigenesis in highly proliferative MDA-MB-231 breast cancer cells. Here, we show that ERp29-induced cancer cell growth arrest is modulated by the interplay between the concomitant phosphorylation of p38 and upregulation of the inhibitor of the interferon-induced, double-stranded RNA-activated protein kinase, $\mathrm{p}^{\mathrm{IPK}}$. In this cell model, ERp29 overexpression significantly downregulates modulators of cell proliferation, namely urokinase plasminogen activator receptor, $\beta_{1}$-integrin and epidermal growth factor receptor. Furthermore, ERp29 significantly $(P<0.001)$ increases phosphorylation of p38 (p-p38) and reduces matrix metalloproteinase-9 secretion. The role of ERp29 in upregulating cyclin-dependent kinase inhibitors ( $p 15$ and p21) and in downregulating cyclin $\mathrm{D}_{2}$ is demonstrated in slowly proliferating ERp29-overexpressing MDA-MB-231 cells, whereas the opposite response was observed in ERp29-knockdown MCF-7 cells. Pharmacological inhibition of p-p38 downregulates p15 and p21 and inhibits elF $2 \alpha$ phosphorylation, indicating a role for $\mathrm{p}-\mathrm{p} 38$ in this process. Furthermore, $\mathrm{p} 58^{\mathrm{IPK}}$ expression was increased in ERp29-overexpressing MDA-MB-231 cells and highly decreased in ERp29-knockdown MCF-7 cells. This upregulation of p58 $8^{\text {IPK }}$ by ERp29 suppresses the activation of p-p38/p-PERK/p-eIF $2 \alpha$ by repressing elF $2 \alpha$ phosphorylation. In fact, reduction of $\mathrm{p} 58^{\mathrm{IPK}}$ expression by RNA interference stimulated elF $2 \alpha$ phosphorylation. The repression of elF $2 \alpha$ phosphorylation by $\mathrm{p} 58^{\mathrm{IPK}}$ prevents ERp29-transfected cells from undergoing ER-dependent apoptosis driven by the activation of ATF4/CHOP/caspase-3. Hence, the interplay between $\mathrm{p} 38$ phosphorylation and $\mathrm{p} 58^{\mathrm{IPK}}$ upregulation has key roles in modulating ERp29-induced cell-growth arrest and survival.

Laboratory Investigation (2012) 92, 200-213; doi:10.1038/labinvest.2011.163; published online 7 November 2011

KEYWORDS: drug resistance; ERp29; ER stress; growth arrest; $\mathrm{p} 38 \alpha, \mathrm{p} 58^{\mathrm{IPK}}$

The endoplasmic reticulum (ER) contains a number of molecular chaperones physiologically involved in protein synthesis and maturation. Of the ER chaperones, protein disulfide isomerase (PDI)-like proteins are characterized by the presence of a thioredoxin domain and function as oxidoreductases, isomerases and chaperones. ${ }^{1}$ Oxido-reductase activity is present in the chaperones with an active-site double-cysteine motif, such as PDI, ERp72 and ERp57. Furthermore, redox-inactive PDI-like proteins including ER protein 29 (ERp29) do not have this motif. ${ }^{2}$ This key structural variation suggests that ERp29 may have different functions in cells, particularly in cancer cells.
Although ERp29 has a key role in both viral unfolding and thyroglobullin secretion, ${ }^{3,4}$ it is also involved in intercellular communication by stabilizing the monomeric gap junction protein connexin $43 .{ }^{5}$ Recently, we have demonstrated a significant role of ERp29 in tumorigenesis by exogenously overexpressing ERp29 in the highly proliferative and invasive MDA-MB-231 cancer cells. ${ }^{6}$ Overexpression of ERp29 in MDA-MB-231 cells results in $G_{0} / G_{1}$ arrest, thus leading to a marked delay in the onset of tumorigenesis in vivo. ${ }^{6}$ Significantly, overexpression of ERp29 increases cell survival when cells are exposed to genotoxic stress induced by doxorubicin and radiation treatment. $^{7-9}$ These studies

\footnotetext{
${ }^{1}$ Department of Pathology, Yong Loo Lin School of Medicine, National University of Singapore, Singapore; ${ }^{2}$ Department of Microbiology, Yong Loo Lin School of Medicine, National University of Singapore, Singapore and ${ }^{3}$ Iron Metabolism and Chelation Program, Department of Pathology and Bosch Institute, University of Sydney, Sydney, New South Wales, Australia

Correspondence: Professor DR Richardson or Dr D Zhang, PhD, Iron Metabolism and Chelation Program, Department of Pathology and Bosch Institute, University of Sydney, Sydney, New South Wales 2006, Australia.
}

E-mail: daohai.zhang@sydney.edu.au

Received 26 June 2011; revised 23 September 2011; accepted 3 October 2011 
indicate a pivotal role of ERp29 in inducing cell growth arrest and cell survival. However, the detailed mechanisms involved remain unknown.

Mechanistic studies in human squamous carcinoma cells have established a close correlation of cell growth arrest with the urokinase plasminogen activator receptor (uPAR), $\beta 1$-integrin, epidermal growth factor receptor (EGFR), extracellular signal-regulated kinase (ERK) and p38 activities. ${ }^{10-13}$ Two important pathways affected by the uPAR- $\beta_{1}$-integrin-EGFR ternary complex include focal adhesion kinase (FAK)/phosphorylated-ERK (p-ERK) and cell division cycle $42(\mathrm{Cdc} 42) /$ phosphorylated-p38 (p-p38). ${ }^{14}$ Activation of $\mathrm{FAK} / \mathrm{p}$-ERK facilitates cell proliferation and tumorigenesis, whereas activation of $\mathrm{Cdc} 42 / \mathrm{p}-\mathrm{p} 38$ promotes $\mathrm{G}_{0} / \mathrm{G}_{1}$ arrest (Figure 1). ${ }^{14}$ The uPAR is defined to be a central regulator of the balance between p38 and ERK activation as downregulation of uPAR favors p38 activation over ERK to inhibit tumor cell proliferation. ${ }^{13,15,16}$ In addition, activating transcription factor $6 \alpha$ (ATF6 $\alpha$ )-Rheb-mTOR signaling, regulated in part by $\mathrm{p} 38$, was found to be essential in maintaining cell survival of quiescent, but not proliferative, squamous carcinoma cells. ${ }^{17}$

Tumor cell growth arrest and survival have also been mechanistically linked to ER stress signaling. ${ }^{18}$ Accumulation of misfolded/unfolded proteins in the ER lumen results in ER stress and subsequently initiates an integrated signal transduction pathway known as the unfolded protein response (UPR) to ameliorate the protein load on the ER. ${ }^{19,20}$ The UPR is mediated by at least three ER proximal sensors: interferon-induced, double-stranded RNA-activated protein kinase (PKR)-related ER kinase (PERK), inositol requiring enzyme-1 (IRE-1) and ATF6. ${ }^{21,22}$ PERK is a serine/threonine

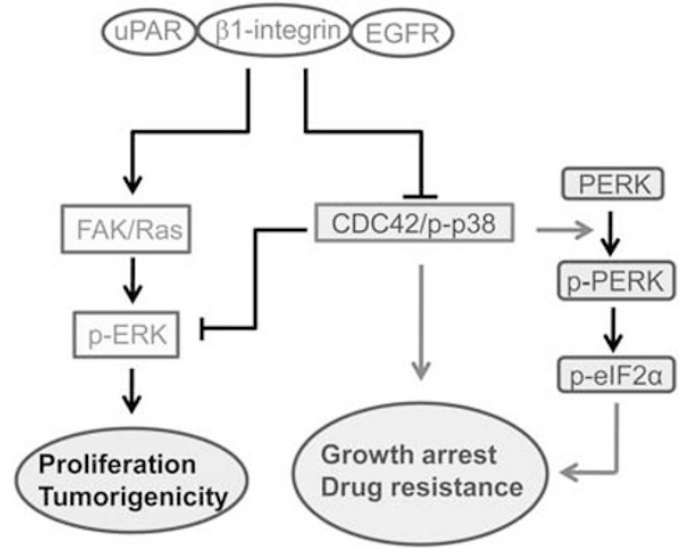

Figure 1 Regulation of tumor cell growth arrest by uPAR- $\beta 1$-integrinEGFR and p38. Loss of the ternary complex formed by the urokinase plasminogen activator receptor (UPAR), $\beta 1$-integrin and epidermal growth factor receptor (EGFR) results in activation of p38 and inhibition of focal adhesion kinase (FAK)/phosphorylated extracellular signal-regulated kinase (p-ERK). Activated p38 enhances phosphorylated PKR-like endoplasmic reticulum kinase ( $p$-PERK)/phosphorylated eukaryotic translation-initiation factor $2 \alpha$ (p-elF $2 \alpha$ ) signaling to induce cell-cycle arrest and drug resistance. kinase that phosphorylates eukaryotic translation-initiation factor $2 \alpha(\mathrm{eIF} 2 \alpha)$ at Ser-51 upon stress and consequently attenuates global protein translation and induces $G_{0} / G_{1}$ arrest. $^{23}$ The role of p38 activation in attenuating cell growth by regulating the PERK/p-eIF $2 \alpha$ pathway has been established in human squamous carcinoma cells. ${ }^{18,24}$ The mechanistic link between ER stress and tumor cell growth arrest through p38 activation suggests an important role of p38-regulated networks in modulating tumor cell quiescence, survival and apoptosis. ${ }^{18,24,25}$ Hence, cells may coordinate growth arrest and survival signals by activating ER stress, leading to resistance to stress-induced death (Figure 1).

In this study, we report a molecular mechanism by which ERp29 inhibits cell proliferation and induces cell survival. We demonstrate that the expression of uPAR- $\beta 1$-integrin-EGFR and its downstream FAK/p-ERK are significantly decreased, whereas $\mathrm{p} 38 \alpha$ is highly phosphorylated in ERp29-overexpressing MDA-MB-231 cells. Activation of p38 $\alpha$ downregulates cyclin $\mathrm{D}_{2}$ and upregulates p15 and p21, which probably mediates the $G_{0} / G_{1}$ arrest observed in our previous studies. ${ }^{6}$ Furthermore, we show that $\mathrm{p} 38 \alpha$ activation by ERp29 negatively regulates the expression of basal eIF2 $\alpha$, whereas upregulation of $\mathrm{p} 58^{\mathrm{IPK}}$ inhibits phosphorylation of eIF $2 \alpha$ and downstream ATF4/CHOP/caspase-3 pro-apoptotic signaling. Thus, for the first time, our results demonstrate that concomitant $\mathrm{p} 38 \alpha$ activation and upregulation of $\mathrm{p} 58^{\mathrm{IPK}}$ and the interplay between these molecules are central in sustaining ERp29-induced cell growth arrest and survival.

\section{MATERIALS AND METHODS Reagents}

The inhibitor of p-p38 kinase activity, SB203580, was purchased from Calbiochem (San Diego, CA). Complete, EDTAfree protease inhibitor cocktail tablets were obtained from Roche Diagnostics (Indianapolis, IN) and phosphatase cocktail inhibitors I and II were from Sigma-Aldrich (St Louis, MO). Geneticin sulfate (G418) and Lipofectamine 2000 transfection reagent were supplied from Invitrogen (Eugene, OR).

\section{Antibodies}

The following antibodies were used in this study: mouse anti-human uPAR (Cat. No. DY807) from R\&D Systems (Minneapolis, $\mathrm{MN}$ ); rabbit anti-human EGFR (C terminus; Cat. No. 1114-1) from Epitomics (Burlingame, CA); rabbit anti-human ERp29 (Cat. No. NB300-523), rabbit anti-human ATF4 (Cat. No. H00000468-AP11) and rabbit anti-human binding immunoglobulin protein (BiP)/GRP78 (Cat. No. 28220002) from Novus Biologicals (Littleton, CO) and mouse anti-human $\beta$-actin (Cat. No. A5441) from SigmaAldrich. The remaining antibodies were all purchased from Cell Signaling Technology (Beverley, MD), namely rabbit anti-human PERK (Cat. No. 3192), rabbit anti-human phospho-PERK (Thr-980; Cat. No. 3179), rabbit anti-human p15 ${ }^{\text {INK4B }}$ (Cat. No. 4822), rabbit anti-human p21 ${ }^{\text {Wafi/Cip1 }}$ 
(Cat. No. 2974), rabbit anti-human $\beta_{1}$-integrin (Cat. No. 4706), rabbit anti-human eIF2 $\alpha$ (Cat. No. 5324), mouse antihuman p-eIF2 $\alpha$ (Ser-51; Cat. No. 3597), rabbit anti-human p58 $8^{\mathrm{IPK}}$ (Cat. No. 2940), rabbit anti-human FAK (Cat. No. 3285) and rabbit anti-human p-FAK (Tyr-397; Cat. No. 3283), rabbit anti-human p38 $\mathrm{MAPK}$ (Cat. No. 2371), mouse anti-human GADD153/CHOP (Cat. No. 2895S), rabbit anti-human phospho-p38 (Thr-180/Tyr-182; Cat. No. 9211) and rabbit anti-human-cleaved caspase-3 (Cat. No. 9664).

\section{Cell Culture}

MDA-MB-231 and MCF-7 breast cancer cell lines were purchased from the American Type Culture Collection (ATCC, Manassas, VA) and maintained in Dulbecco's modified Eagle's medium (DMEM) supplemented with 10\% fetal bovine serum (FBS, Invitrogen).

MDA-MB-231 cells transfected with pcDNA/ERp29 or pcDNA, and MCF-7 cells transfected with shRNA/ERp29 or scrambled control shRNA were generated as described previously. ${ }^{6}$ All transfected cells were maintained in DMEM supplemented with $10 \%$ FBS and G418 (Invitrogen; $2 \mathrm{mg} / \mathrm{ml}$ for MDA-MB-231 transfectants, or $1 \mathrm{mg} / \mathrm{ml}$ for MCF-7 transfectants). Cells were cultured at $37^{\circ} \mathrm{C}$ in a $5 \% \mathrm{CO}_{2} / 95 \%$ air atmosphere in a humidified incubator.

\section{Treatment with a Pharmacological Inhibitor of p-p38 Kinase Activity}

Cells were seeded $\left(5 \times 10^{5} /\right.$ well $)$ in 6 -well plates and incubated at $37^{\circ} \mathrm{C}$ in the $\mathrm{CO}_{2}$ incubator described above. When cells reached $\sim 70 \%$ confluence, these cultures were treated with SB203580 $(40 \mu \mathrm{M})$ or control medium containing the same final concentration of dimethyl sulfoxide (DMSO) used to dissolve this inhibitor (ie, $0.1 \%$ ), as described previously. ${ }^{26}$ After a $24 \mathrm{~h} / 37^{\circ} \mathrm{C}$ incubation, cells were collected and total protein was extracted for western blot analysis.

\section{RNA Interference and Transfection}

Small-interfering RNAs (siRNAs) against $\mathrm{p} 58^{\mathrm{IPK}}$ and the scrambled control siRNA (Cell Signaling Technology) were used for gene-knockdown studies according to standard procedures, as described previously. ${ }^{9}$ Cells at $\sim 70 \%$ confluence were transfected with siRNA $(100 \mathrm{nM})$ using Lipofectamine 2000 transfection reagent (Invitrogen) according to the manufacturer's instructions. Thereafter, 24 or $48 \mathrm{~h}$ after transfection, cells were harvested for western blot analysis.

\section{Cell Viability Assay}

Cell viability was analyzed using the 3-(4-5-dimethylthiazol2-yl)-5-(3-carboxymethoxy-phenyl)-2-(4-sulfophenyl)-2Htetrazolium salt (MTS) assay kit (Promega Corporation, Madison, WI) according to the manufacturer's instructions. In brief, cells $\left(5 \times 10^{5}\right.$ cells/well $)$ were seeded in 6-well plates. Cells at $\sim 70 \%$ confluence were treated with $\mathrm{p} 58^{\mathrm{IPK}} / \mathrm{siRNA}$ or control siRNA for $24 \mathrm{~h} / 37^{\circ} \mathrm{C}$ and cell viability was assessed. In other experiments, these siRNA-treated cells were further treated with doxorubicin $(200 \mathrm{nM})$ or control medium containing DMSO (ie, $0.1 \% \mathrm{v} / \mathrm{v}$ ) for $24 \mathrm{~h} / 37^{\circ} \mathrm{C}$. Cell viability was then assessed through incubation with MTS solution for $4 \mathrm{~h} / 37^{\circ} \mathrm{C}$, and the absorbance of formazan at $492 \mathrm{~nm}$ was measured using an Infinite F200 microplate reader (TECAN Austria GmbH, Grodig, Austria). The absorbance of cells treated with scrambled siRNA was defined as $100 \%$ survival (control), and the remaining data were expressed as a percentage of this control. Viable cell counts using Trypan blue validated the results obtained with MTS.

\section{Western Blot Analysis}

Western blotting was performed by a standard protocol, as described previously. ${ }^{6,9,26}$ In brief, cell lysates were extracted with radio-immunoprecipitation buffer (1\% Igepal, $1 \%$ sodium deoxycholate, $0.15 \mathrm{M}$ sodium chloride, $0.01 \mathrm{M}$ SDS, $\mathrm{pH}$ 7.2 and $2 \mathrm{mM}$ EDTA), supplemented with protease inhibitors (Roche Diagnostics) and phosphatase cocktail inhibitors I and II (1:100, Sigma-Aldrich). Cell lysates were centrifuged at $13000 \times g$ for $20 \mathrm{~min} / 4^{\circ} \mathrm{C}$ and the protein-containing supernatant was collected. Total proteins $(50 \mu \mathrm{g} /$ lane) were separated by $10 \%$ SDS-PAGE and transferred onto PVDF membranes. Membranes were blocked with $5 \%$ skim milk in Tris-buffered saline buffer with $0.1 \%$ Tween 20 for $1 \mathrm{~h}$ at room temperature and probed with the indicated primary antibodies. Goat anti-mouse horseradish peroxidase (HRP; Cat. No. 12-349; Upstate Biotechnology, Lake Placid, NY) or goat anti-rabbit HRP secondary antibody (Cat. No. 62-1820; ZyMED Laboratories, San Francisco, CA) was used as secondary antibodies. The chemiluminescent signal was developed with Supersignal West Pico Chemiluminescent Substrate (Pierce, Rockford, IL). Signal intensity was analyzed using GeneTools software (Syngene, Frederick, MD). The level of $\beta$-actin was used as a loading control and was not altered under any of the conditions used.

\section{Zymography}

Cells at $\sim 70 \%$ confluence were washed twice with PBS buffer ( $\mathrm{pH}$ 7.4) and then incubated with serum-free DMEM for $48 \mathrm{~h} / 37^{\circ} \mathrm{C}$. The conditioned medium was collected and centrifuged at $3000 \times \mathrm{g} / 15 \mathrm{~min} / 4^{\circ} \mathrm{C}$ to remove cell debris. The supernatant was concentrated 80-100-fold using a Biomax Ultrafree Centrifugal Filter Unit (Millipore, Bedford, MA) with a $10-\mathrm{kDa}$ pore diameter cutoff. The total secreted proteins $(50 \mu \mathrm{g})$ were mixed with SDS sample buffer in the absence of reducing agents and resolved in $7.5 \%$ polyacrylamide gels containing $0.1 \%$ gelatin under non-reducing conditions. Matrix metalloproteinase (MMP) activity was assessed by gelatin zymography. ${ }^{27}$ In brief, gels were washed for $1 \mathrm{~h}$ at room temperature with $50 \mathrm{mM}$ Tris- $\mathrm{HCl}$ buffer $(\mathrm{pH}$ 7.5) containing $2.5 \%(\mathrm{v} / \mathrm{v})$ Triton $\mathrm{X}-100$ and $5 \mathrm{mM} \mathrm{CaCl}$ and then washed extensively with Milli-Q water. After removing SDS, gels were further incubated overnight at $37^{\circ} \mathrm{C}$ in digestion buffer $\left(50 \mathrm{mM}\right.$ Tris, $\mathrm{pH} 7.5,5 \mathrm{mM} \mathrm{CaCl}_{2}$, $0.1 \mathrm{mM} \mathrm{ZnCl}, 150 \mathrm{mM} \mathrm{NaCl}$ ) to allow proteolysis of the 
gelatin substrate. This was followed by staining with $5 \%$ $(w / v)$ Coomassie Brilliant Blue R-250 and de-staining in methanol/acetic acid/water (10:10:80). The gelatinolytic activities were detected as clear bands against a blue background.

\section{Statistical Analysis}

Student's $t$-test was used to analyze the data. Results were considered statistically significant when $P<0.05$. All cell culture experiments were performed in triplicate. Data are presented as mean \pm s.d.

\section{RESULTS}

\section{Overexpression of ERp29 Significantly Reduces the} Level of the uPAR- $\beta_{1}$-Integrin-EGFR Complex

We previously reported that overexpression of ERp29 in MDA-MB-231 cells resulted in cell growth arrest and inhibition of tumor formation. ${ }^{6}$ Mechanistic studies at the mRNA level revealed downregulation of uPAR, $\beta_{1}$-integrin and EGFR in ERp29-induced MDA-MB-231 dormant-like cells. ${ }^{6}$ In this study, immunoblotting analysis has further demonstrated a marked and significant $(P<0.001)$ decrease in protein expression of uPAR, $\beta_{1}$-integrin and EGFR in these dormant-like cells (clones $\mathrm{B}$ and $\mathrm{E}$ ) relative to empty vectortransfected control cells (Ctrl; Figure 2a).

Notably, uPAR is an important membrane receptor in regulating both cell growth and invasion. ${ }^{28,29}$ Its expression is highly regulated by the v-ets erythroblastosis virus E26 oncogene homolog 1 (Ets-1) in invasive breast cancer cells. ${ }^{30}$ Here, we have shown that Ets-1 was significantly $(P<0.01)$ downregulated by ERp29 (Figure 2a), further supporting a mechanistic link of ERp29 in attenuating uPAR in these slowly proliferating ERp29-transfected cells. Given that activation or loss of the uPAR- $\beta_{1}$-integrin-EGFR complex decides the fate of the cell between proliferation and growth arrest (Figure 1), we further investigated whether ERp29mediated cell growth arrest in MDA-MB-231 cells was associated with the interruption of downstream signaling regulated by this complex.

\section{Overexpression of ERp29 Activates p38 Phosphorylation and Decreases FAK Expression and MMP-9 Secretion}

Phosphorylation of ERK (p-ERK) was significantly inhibited in ERp29-overexpressing MDA-MB-231 cells. ${ }^{6}$ Here, we also show that FAK expression and phosphorylation were significantly $(P<0.01)$ reduced by $\sim 2.5$ - and $\sim 3.2$-fold in these cells compared with vector-transfected MDA-MB-231 control cells (Figure $2 \mathrm{~b}$ ). In parallel, the level of phosphorylation of p38 was significantly $(P<0.001)$ enhanced by $\sim 9-10$-fold, whereas the expression of basal p38 $\alpha$ was significantly $(P<0.001)$ decreased in ERp29-overexpressing MDA-MB-23 cells (Figure 2b). The role of ERp29 in regulating p38 expression and phosphorylation was further verified in MCF-7 cells, which show a dormant-like state in three-dimensional cell cultures. ${ }^{31}$ As shown in Figure 2c, knockdown of ERp29 resulted in a significant reduction of p-p38 (3-fold, $P<0.01$ ) and upregulation $(1.8$-fold, $P<0.05$ ) of basal p38 $\alpha$. Furthermore, ERp29 knockdown in MCF-7 cells significantly increased FAK expression $(\sim 2.3$-fold, $P<0.01)$ and phosphorylation $(\sim 2.9$-fold, $P<0.01)$ relative to these cells treated with scrambled control shRNA (shCtrl; Figure 2c). Consistent with the studies that inhibition of FAK led to cell dormancy in human squamous carcinoma cells, ${ }^{32}$ these data indicate that knockdown of ERp29 could enhance cell proliferation by activating FAK, as we have previously shown in ERp29-knockdown MCF-7 cells. ${ }^{6}$

Our data showed that overexpression of ERp29 led to an $\sim 2.5$-fold decrease in p-ERK ${ }^{6}$ and 9-fold increase in p-p38 (Figure 2b) in ERp29-transfected MDA-MB-231 cells. Given the importance of the signaling balance between p38 and ERK activation in deciding cell fate, eg, proliferation and growth arrest, ${ }^{14}$ these findings above indicate that overexpression of ERp29 in MDA-MB-231 cells markedly interrupts this signaling balance, leading to induction of cell growth arrest (Figure 1).

It has been reported that MMPs are important downstream molecules regulated by uPAR- $\beta_{1}$-integrin, p38 and ERK signaling and have critical roles in matrix degradation and cellular invasion. ${ }^{33,34}$ To determine whether the reduced expression of uPAR- $\beta_{1}$-integrin and increased p-p38 levels in ERp29-overexpressing MDA-MB-231 cells result in the loss of MMP activity, the latter cell type (clone B as an example) and empty vector-transfected control cells were serum starved for $48 \mathrm{~h}$ and the secretion of MMPs was assessed using gelatin zymography. As shown in Figure 2d, ERp29transfected cells (clone B) showed a significant $(P<0.001)$ 5.3-fold decrease in MMP-9 activity based on the intensity of the negatively stained band. A similar effect was also found for clone $\mathrm{E}$ (data not shown). However, the activity of MMP-2 was not significantly $(P>0.05)$ affected. These results further support our previous demonstration of a less invasive phenotype in ERp29-overexpressing MDA-MB-231 cells relative to these cells transfected with the empty vector. ${ }^{6}$

\section{p38 $\alpha$ Activation Induces Upregulation of the Cyclin- Dependent Kinase Inhibitors p15 and p21 and Downregulation of Cyclin $D_{\mathbf{2}}$}

To further establish the molecular alterations in ERp29overexpressing MDA-MB-231 cells, the expressions of cyclin $\mathrm{D}_{1} / \mathrm{D}_{2}$ and the cyclin-dependent kinase inhibitors, p15 and p21, were examined. Cyclin $D_{1}$ was significantly $(P<0.05)$ reduced in clone $\mathrm{B}$, but to a lesser extent, in clone $\mathrm{E}$ of ERp29-overexpressing MDA-MB-231 cells compared with empty vector-transfected control cells (Figure $3 \mathrm{a}$ ). In addition, consistent with our earlier report that cyclin $D_{2}$ mRNA levels were markedly reduced by ERp29 overexpression, ${ }^{6}$ we demonstrated that the protein expression of cyclin $\mathrm{D}_{2}$ was significantly $(P<0.01-0.001)$ decreased in both clones $\mathrm{B}$ and E (Figure 3a). On the other hand, knockdown of ERp29 by shRNA in MCF-7 cells relative to the scrambled control 

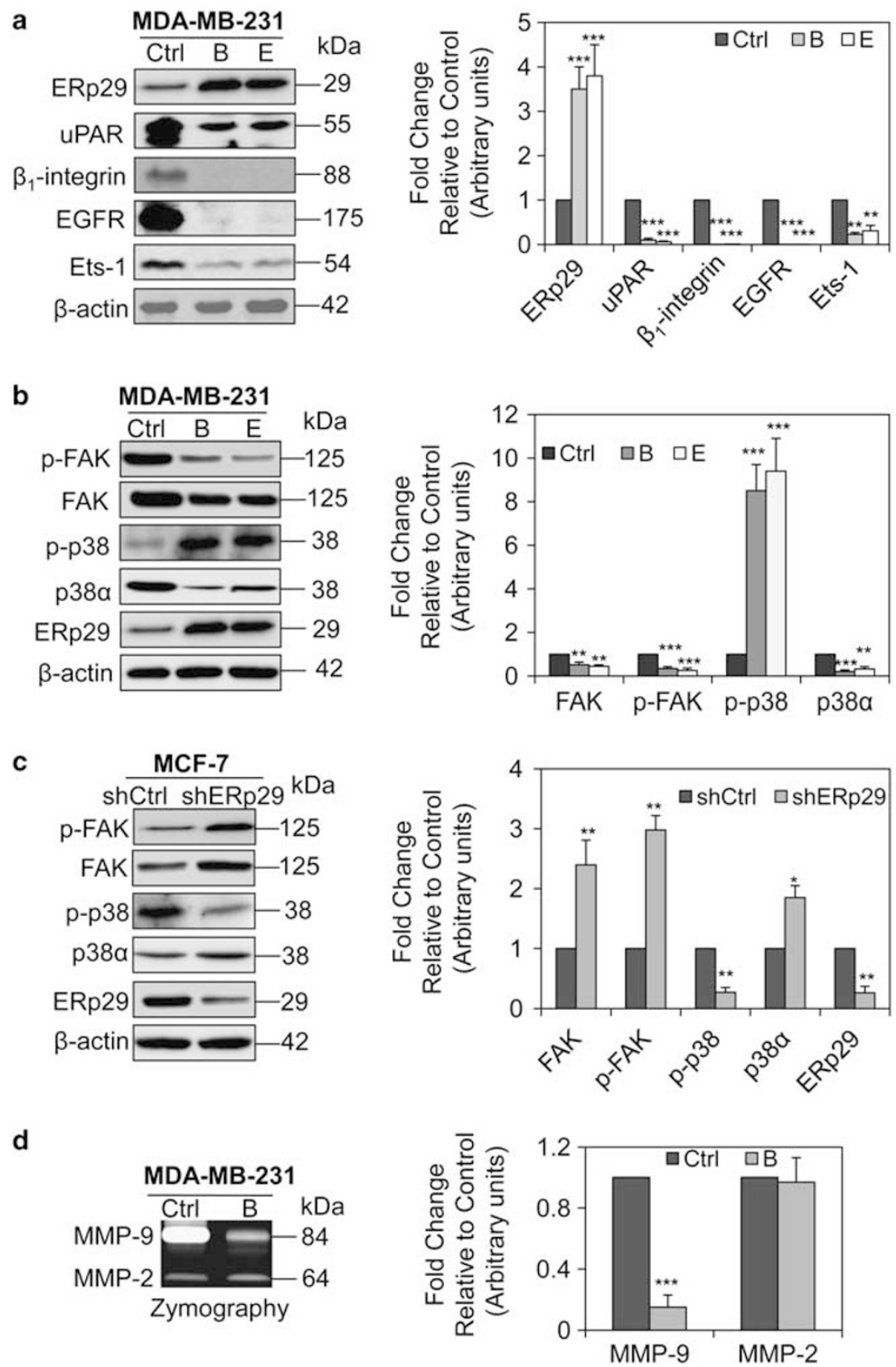

Figure 2 Overexpression of ERp29 decreases the level of UPAR, $\beta 1$-integrin and EGFR and activates p38 phosphorylation. (a) Expression of the UPAR- $\beta 1$-integrin-EGFR complex is markedly and significantly $(P<0.001)$ reduced in ERp29-overexpressing MDA-MB-231 cells (clones $B$ and E). In these slowly proliferating cells, the protein expression of Ets-1, a transcription factor of uPAR, was also reduced by ERp29 overexpression, leading to a downregulation of uPAR relative to cells transfected with the empty vector control (Ctrl). (b) Overexpression of ERp29 in MDA-MB-231 cells (clones B and E) attenuates the expression of FAK, p-FAK and basal p38 $\alpha$, but markedly and significantly stimulates p38 phosphorylation relative to the empty vector Ctrl. (c) Knockdown of ERp29 by shRNA in MCF-7 cells increases FAK expression and phosphorylation and protein expression of basal p38 $\alpha$, while reducing p38 phosphorylation relative to cells transfected with a scrambled control shRNA. (d) Zymography of matrix metalloproteinases (MMPs). MDA-MB-231 cells transfected with ERp29 or the empty vector were serum starved for $48 \mathrm{~h} / 37^{\circ} \mathrm{C}$ and the secreted MMPs were then assayed by gelatin zymography, as described in the 'Materials and Methods' section. It must be noted that MMP-9 activity is significantly reduced in ERp29-overexpressing MDA-MB-231 cells (clone B) relative to cells transfected with the empty vector Ctrl. Densitometric data represent the fold change of the levels in test cells relative to those in Ctrl cells. Results are mean \pm s.d. (three experiments). ${ }^{\star} P<0.05,{ }^{* *} P<0.01,{ }^{* * *} P<0.001$.

shRNA, resulted in 2.3-fold upregulation $(P<0.01)$ of cyclin $\mathrm{D}_{2}$, with no significant effect on cyclin $\mathrm{D}_{1}$ expression (Figure 3b).
We also investigated the role of ERp29 in regulating the protein expression of p15 and p21, which were upregulated by ERp29 at the mRNA level. ${ }^{6}$ As shown in Figure 3a, both 

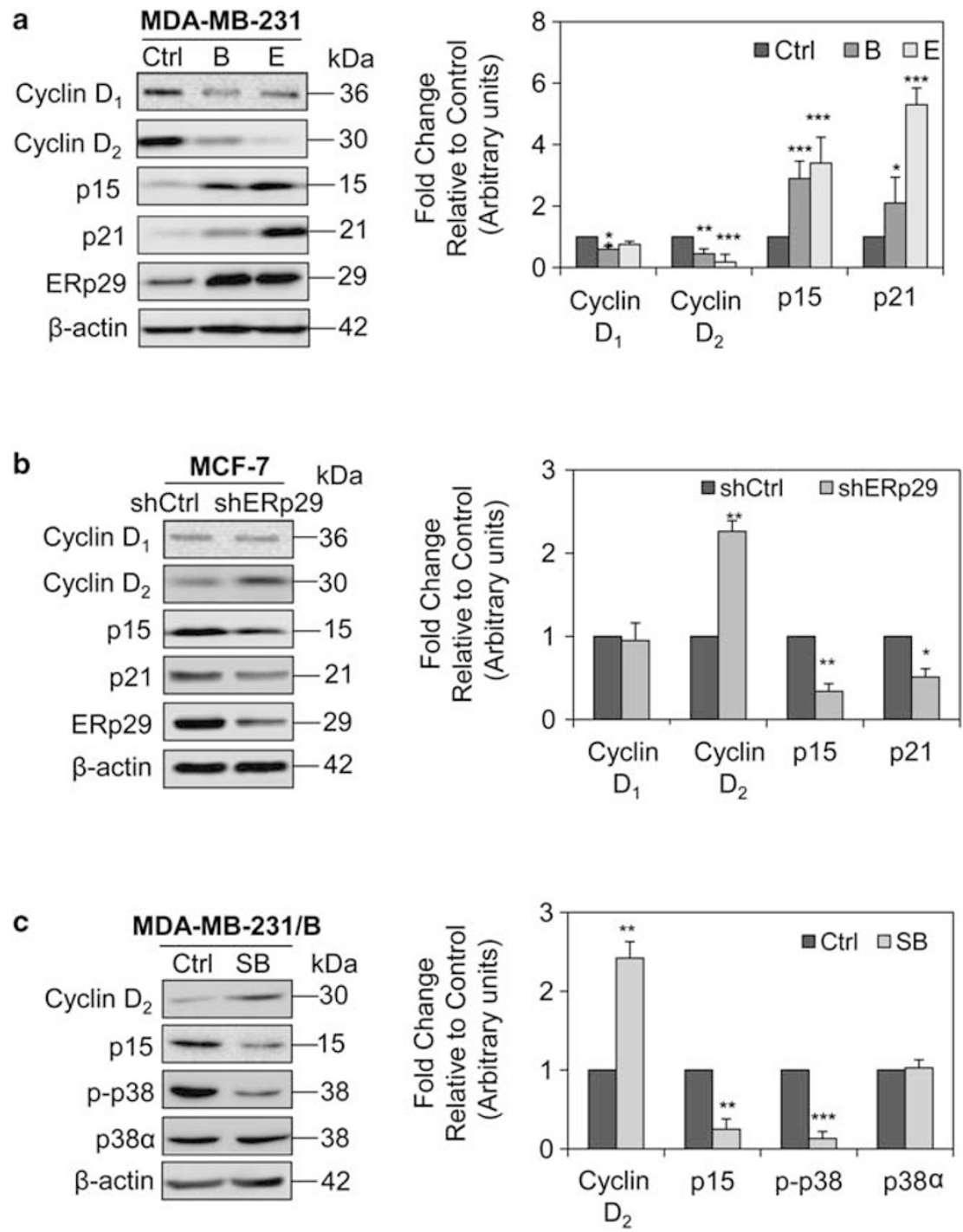

Figure 3 ERp29 affects check-point protein expression. (a) Overexpression of ERp29 in MDA-MB-231 cells (clones B and E) significantly decreases cyclin $\mathrm{D}_{2}$ expression and increases p15 and p21 protein expression relative to cells transfected with the empty vector control (Ctrl). (b) Knockdown of ERp29 in MCF-7 cells by shRNA increases cyclin $D_{2}$ expression and decreases p15 and p21 protein levels relative to cells transfected with the scrambled Ctrl shRNA (shCtrl). (c) Inhibition of p-p38 kinase activity by incubation of ERp29-overexpressing MDA-MB-231 cells (clone B) with the inhibitor, SB203580 (SB; $40 \mu$ M), for $24 \mathrm{~h} / 37^{\circ} \mathrm{C}$ results in the upregulation of cyclin $D_{2}$ and downregulation of p15 relative to these cells incubated in the same manner with the control medium alone. Densitometry results are expressed as a fold change relative to the control and are mean \pm s.d. (three experiments). ${ }^{\star} P<0.05,{ }^{* \star P}<0.01$, ${ }_{* * * P}<0.001$.

the expressions of p15 and p21 were significantly $(P<0.05-$ 0.001 ) increased in slowly proliferating ERp29-transfected MDA-MB-231 cells. Furthermore, knockdown of ERp29 in MCF-7 cells led to a significant $(P<0.01) 3$-fold reduction of p15 and a 2 -fold decrease $(P<0.05)$ of p21 (Figure $3 b)$. These results further substantiate the molecular mechanisms underlying the ERp29-induced $G_{0} / G_{1}$ arrest which we showed previously. ${ }^{6}$

To further establish whether the marked increase in p38 phosphorylation was involved in ERp29-mediated upregulation of p15 and downregulation of cyclin $\mathrm{D}_{2}$ in slowly proliferating ERp29-overexpressing MDA-MB-231 cells (clone B), these cells were treated with a specific inhibitor of p38 phosphorylation and kinase activity, namely: SB203580 $(40 \mu \mathrm{M}) \cdot{ }^{26,34,35}$ After $24 \mathrm{~h}$ of treatment, cells were harvested and protein expression was assessed by western blotting. As shown in Figure $3 c$, concurrent with a significant $(P<0.001)$ reduction of p38 phosphorylation, cyclin $\mathrm{D}_{2}$ was highly increased by 2.4 -fold $(P<0.01)$ in inhibitor-treated ERp29overexpressing MDA-MB-231 cells, compared with relevant control cells, whereas the expression of p15 was highly decreased by 4 -fold $(P<0.01)$. These results indicate that $\mathrm{p} 38$ phosphorylation is critical in modulating the expression of these check-point proteins in cells subjected to ERp29-induced $\mathrm{G}_{0} / \mathrm{G}_{1}$ arrest. $^{6}$

\section{Activation of p38 Inhibits Basal elF2 $\alpha$ Expression}

It has been demonstrated that activated p38 functionally links ER stress signaling in modulating cell dormancy, survival and 
apoptosis. ${ }^{18}$ Moreover, inactivation of eIF2 $\alpha$ by phosphorylation induces $G_{0} / G_{1}$ arrest and cell survival by blocking cyclin $\mathrm{D}_{1} / \mathrm{D}_{2}$ translation/stability. ${ }^{23}$ Our current studies (Figure $4 \mathrm{a}$, left immunoblot panel) revealed that overexpression of ERp29 in MDA-MB-231 cells (clone B) significantly $(P<0.01)$ inhibited the expression of both p-eIF $2 \alpha$ and eIF $2 \alpha$. This is further supported by experiments demonstrating that knockdown of ERp29 in MCF-7 cells significantly $(P<0.05)$ increased the expression of both p-eIF $2 \alpha$ and eIF $2 \alpha$ relative to cells treated with the scrambled control (Figure $4 \mathrm{a}$, right immunoblot panel). These data demonstrate that ERp29 inversely regulates the expression of basal eIF $2 \alpha$ in these cell models. However, it is notable that overexpression of ERp29 in MDA-MB-231 cells did not markedly change the relative overall ratio of phosphorylated to basal eIF2 $\alpha$ (p-eIF2 $\alpha /$ eIF2 $\alpha$; Figure $4 a$, see densitometric analysis). Interestingly, the shRNA-mediated reduction of ERp29 expression in MCF-7 cells significantly $(P<0.05)$ increased the relative phosphorylation of eIF $2 \alpha$ (p-eIF2 $\alpha /$ eIF $2 \alpha$ ) by 1.8 -fold (Figure $4 \mathrm{a}$, see densitometric analysis), implicating the possible activation of PERK/p-eIF2 $\alpha$ when ERp29 was knocked down. Hence, ERp29 expression could potentially attenuate activation of the PERK/p-eIF2 $\alpha$ pathway in ERp29-overexpressing MDA-MB-231 cells.
As inhibition of p38 phosphorylation increases cyclin $\mathrm{D}_{2}$ expression and decreases p15 levels in MDA-MB-231 cells (Figure 3c), we next investigated the role of p38 phosphorylation in ERp29-mediated downregulation of eIF2 $\alpha$ expression. To this end, p-p38 kinase activity was blocked for $24 \mathrm{~h}$ with the inhibitor, SB203580 $(40 \mu \mathrm{M})$, in ERp29-overexpressing MDA-MB-231 cells (clone B) and in MCF-7 cells. As shown in Figure $4 \mathrm{~b}$ (left immunoblot panel), treatment of ERp29-overexpressing MDA-MB-231 cells (clone B) with the inhibitor resulted in a marked reduction $(P<0.001)$ of p-eIF $2 \alpha$, whereas basal eIF $2 \alpha$ was significantly $(P<0.01)$ increased. Thus, the relative phosphorylation of eIF $2 \alpha$ was significantly $(P<0.01)$ reduced by 2.9 -fold in inhibitor-treated clone B cells when compared with these cells treated with vehicle control (Figure $4 \mathrm{~b}$, see densitometric analysis).

Similar results were also observed in MCF-7 cells treated with this p-p38 kinase activity inhibitor (Figure $4 \mathrm{~b}$, right immunoblot panel), namely there was a significant $(P<0.01)$ 2.8 -fold increase of basal eIF2 $\alpha$ expression and a significant $(P<0.001) 6$-fold reduction of the relative phosphorylation of eIF $2 \alpha$ compared with MCF-7 cells treated with the control medium (Figure $4 \mathrm{~b}$, see densitometric analysis). These data suggest that p38 phosphorylation negatively regulates the
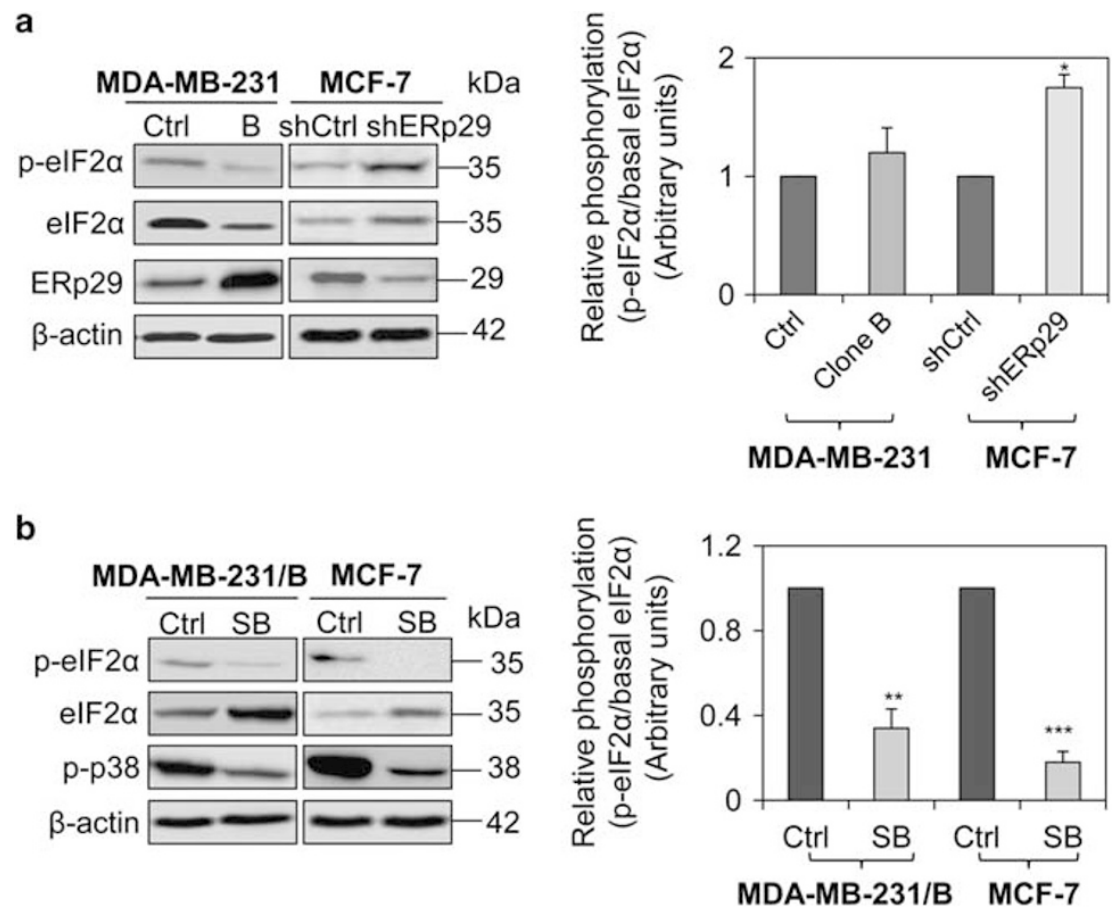

Figure 4 p38 phosphorylation involves ERp29-mediated downregulation of elF2 $\alpha$. (a) Effect of ERp29 on elF2 $\alpha$ phosphorylation and protein expression measured by western analysis. Expression of basal elF $2 \alpha$ is highly decreased, whereas phosphorylation of elF $2 \alpha$ relative to its basal level (ie, p-elF2 $\alpha /$ elF2 $\alpha$ ) is similar in ERp29-overexpressing MDA-MB-231 cells (clone B) to that observed in control (Ctrl) cells transfected with the empty vector (left immunoblot). Knockdown of ERp29 in MCF-7 cells using shERp29 results in an upregulation of basal elF2 $\alpha$ and an increase in the phosphorylation of elF2 $\alpha$ relative to cells treated with the scrambled Ctrl shRNA (shCtrl; right immunoblot). (b) Inhibition of p-p38 kinase activity after incubation with the inhibitor, SB203580 $\left(\mathrm{SB} ; 40 \mu \mathrm{M}\right.$ ), for $24 \mathrm{~h} / 37^{\circ} \mathrm{C}$ increases expression of basal elF $2 \alpha$, but markedly reduces its phosphorylation in both ERp29 overexpressing MDA-MB-231 cells and also MCF-7 cells compared with cells treated with the control medium. Densitometric data are shown as a fold change of relative phosphorylation of elF $2 \alpha$ (ie, p-elF $2 \alpha /$ elF $2 \alpha$ ) normalized to the control. Results are mean \pm s.d. (three experiments). ${ }^{\star} P<0.05,{ }^{* *} P<0.01,{ }^{* * *} P<0.001$. 
expression of basal eIF $2 \alpha$, but positively regulates eIF $2 \alpha$ phosphorylation.

Surprisingly, marked upregulation of p-p38 levels in ERp29-overexpressing MDA-MB-231 cells (clones B and E, as indicated in Figure $2 b$ ) was unable to increase eIF $2 \alpha$ phosphorylation (Figure $4 \mathrm{a}$, left immunoblot panel). Furthermore, reduction of p-p38 (Figure 2c) in ERp29-knockdown MCF-7 cells was unable to decrease the relative phosphorylation of eIF $2 \alpha$ (Figure $4 \mathrm{a}$, right immunoblot panel). Instead, the relative phosphorylation of eIF $2 \alpha$ was significantly $(P<0.05)$ increased (Figure $4 \mathrm{a}$, see densitometric analysis). These observations indicate that other molecules may interfere with the phosphorylation of eIF $2 \alpha$ regulated by $\mathrm{p}-\mathrm{p} 38$.

\section{ERp29-Mediated Upregulation of p58 ${ }^{\text {IPK }}$ Counteracts elF $2 \alpha$ Phosphorylation by p-p38}

Considering the apparently contradictory results above in which eIF $2 \alpha$ phosphorylation status did not alter appro- priately in response to alterations in p-p38, we then investigated the possibility that other factors functionally counteract eIF $2 \alpha$ phosphorylation by p-p38. These factors may be concomitantly regulated by ERp 29 and could be responsible for the inhibition of eIF $2 \alpha$ phosphorylation in cells. This hypothesis was assessed in ERp29-overexpressing MDA-MB-231 cells considering our previous studies which demonstrated that ERp29 overexpression led to activation of $\mathrm{XBP}-1 .{ }^{9}$ Indeed, one ER protein that is specifically regulated by XBP-1 is the inhibitor of the interferon-induced, doublestranded RNA-activated protein kinase, $\mathrm{p} 58^{\mathrm{IPK}} .{ }^{36}$ Of interest, p5 $8^{\mathrm{IPK}}$ can directly bind to PERK to inhibit PERK phosphorylation, resulting in inhibition of eIF $2 \alpha$ phosphorylation. ${ }^{37,38}$

Considering the potential role of p58 $8^{\mathrm{IPK}}$ in eIF2 $\alpha$ phosphorylation, we first examined $\mathrm{p} 58^{\mathrm{IPK}}$ expression in ERp29overexpressing MDA-MB-231 cells, and second, we assessed the effect of $\mathrm{p} 58^{\mathrm{IPK}}$ on regulating eIF $2 \alpha$ phosphorylation. As shown in Figure $5 \mathrm{a}, \mathrm{p} 58^{\mathrm{IPK}}$ was significantly $(P<0.01)$ a

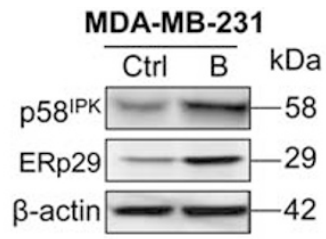

b

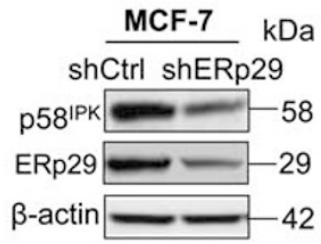

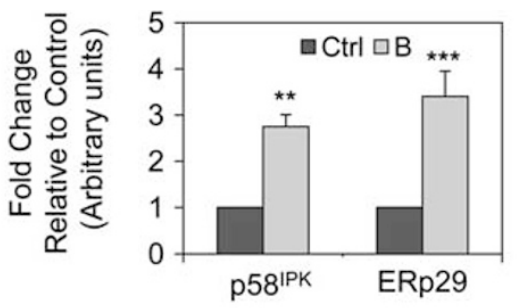
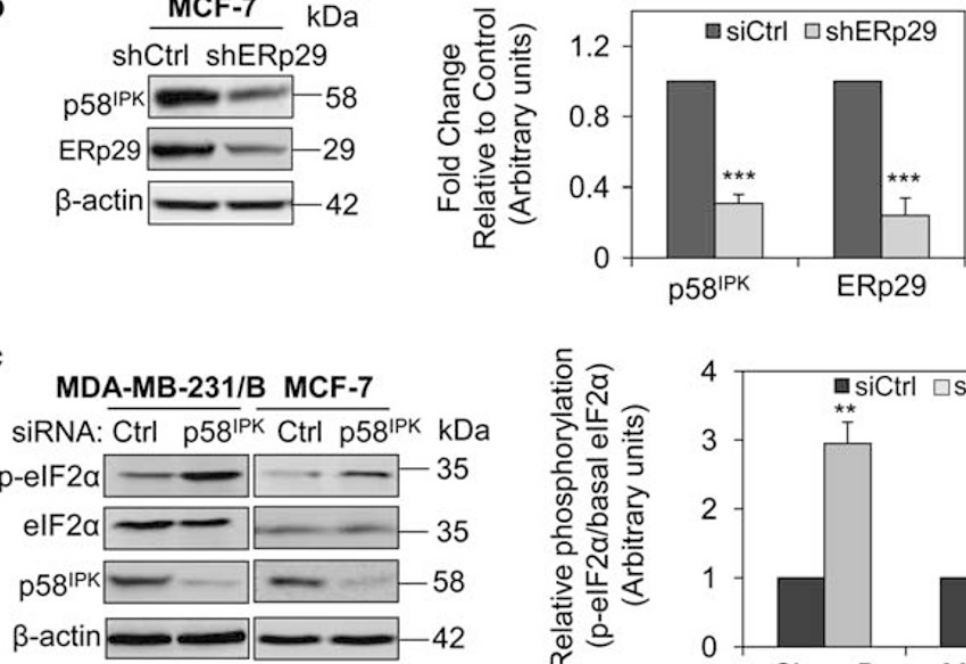

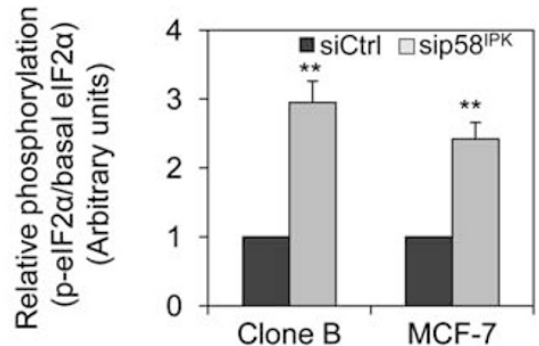

Figure 5 ERp29 overexpression upregulates the expression of $\mathrm{p} 58^{\mathrm{IPK}}$ and silencing of $\mathrm{p} 58^{\mathrm{IPK}}$ stimulates elF2 $\alpha$ phosphorylation. (a) Overexpression of ERp29 in MDA-MB-231 cells markedly upregulates p58 ${ }^{\mathrm{IPK}}$ relative to control cells transfected with the empty vector alone. (b) The opposite effect on p58 $8^{\mathrm{IPK}}$ is observed when ERp29 was knocked down by shRNA in MCF-7 cells relative to cells transfected with the scrambled control shRNA (shCtrl). Densitometric data represent the fold change of $\mathrm{p} 58^{\mathrm{IPK}}$ after normalization to $\beta$-actin, compared with control cells. (c) Silencing of p58 ${ }^{\mathrm{IPK}}$ enhances elF2 $\alpha$ phosphorylation. ERp29-overexpressing MDA-MB-231 cells (clone B) or MCF-7 cells were treated with $100 \mathrm{nM}$ of $\mathrm{p}^{\mathrm{P} 8^{\mathrm{IPK}}}-\mathrm{specific}$ siRNA (p58 ${ }^{\mathrm{IPK}} / \mathrm{siRNA}$ ) or scrambled siRNA for $48 \mathrm{~h} / 37^{\circ} \mathrm{C}$ and the expression of proteins was analyzed by western blotting. As indicated, reduction of p58 $8^{\mathrm{IPK}}$ by siRNA significantly increased the phosphorylation of elF $2 \alpha$ without significantly affecting basal elF $2 \alpha$ levels. Data are presented as a fold change of relative phosphorylation of elF $2 \alpha$ (p-elF $2 \alpha / \mathrm{elF} 2 \alpha$ ) in $\mathrm{p} 58^{\mathrm{IPK}} / \mathrm{siRNA}$-treated cells normalized to control cells. Results are mean \pm s.d. (three experiments). ${ }^{* *} P<0.01,{ }^{* * *} P<0.001$. 
upregulated by 2.8-fold in ERp29-overexpressing MDA-MB231 cells (clone B). Furthermore, knockdown of ERp29 in MCF-7 cells caused a significant $(P<0.001)$ reduction in $\mathrm{p} 58^{\mathrm{IPK}}$ expression (Figure $5 \mathrm{~b}$ ).

To examine whether upregulation of $\mathrm{p} 58^{\mathrm{IPK}}$ is involved in the inhibition of eIF2 $\alpha$ phosphorylation, ERp29-overexpressing MDA-MB-231 cells (clone B) and MCF-7 cells were treated with $\mathrm{p} 58^{\mathrm{IPK}}$ siRNA or scrambled control siRNA for $48 \mathrm{~h}$ and the expression and phosphorylation of eIF $2 \alpha$ were assessed. As demonstrated in Figure $5 c$, when upregulated p5 $8^{\mathrm{IPK}}$ was silenced with siRNA in ERp29-overexpressing MDA-MB-231 cells (clone B), the level of p-eIF2 $\alpha$ was significantly $(P<0.01)$ increased without significantly affecting the expression of basal eIF $2 \alpha$ (Figure $5 c$, left immunoblot panel). In fact, the relative phosphorylation of eIF $2 \alpha v s$ basal eIF2 $\alpha$ expression was significantly $(P<0.01)$ increased by 2.9-fold (Figure 5c, see densitometric analysis). Similar results

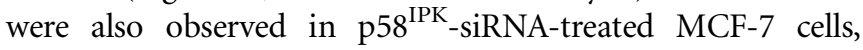

namely silencing of $\mathrm{p} 58^{\mathrm{IPK}}$ significantly $(P<0.01)$ stimulated eIF $2 \alpha$ phosphorylation by 2.6 -fold compared with cells treated with scrambled siRNA (Figure $5 c$, right immunoblot panel), whereas basal eIF $2 \alpha$ was not significantly affected. Consequently, this resulted in a significant $(P<0.01) 2.5$-fold increase in the relative phosphorylation of eIF $2 \alpha v s$ basal eIF $2 \alpha$ expression (Figure $5 c$, see densitometric analysis). These results indicate that the upregulation of $\mathrm{p} 58^{\mathrm{IPK}}$ has an important role in inhibiting eIF2 $\alpha$ phosphorylation in these ERp29overexpressing slow-proliferating cells.

\section{Effect of ERp29 on the Expression of Other ER Stress-Related Molecules}

In addition to $\mathrm{p} 58^{\mathrm{IPK}}$, we also examined the effect of ERp29 on the expression of other ER stress-related molecules. As shown in Figure 6a, the expression of basal PERK was increased by 2.4 -fold $(P<0.01)$, whereas p-PERK was only slightly increased (1.3-fold, $P>0.05)$ in ERp29-over-
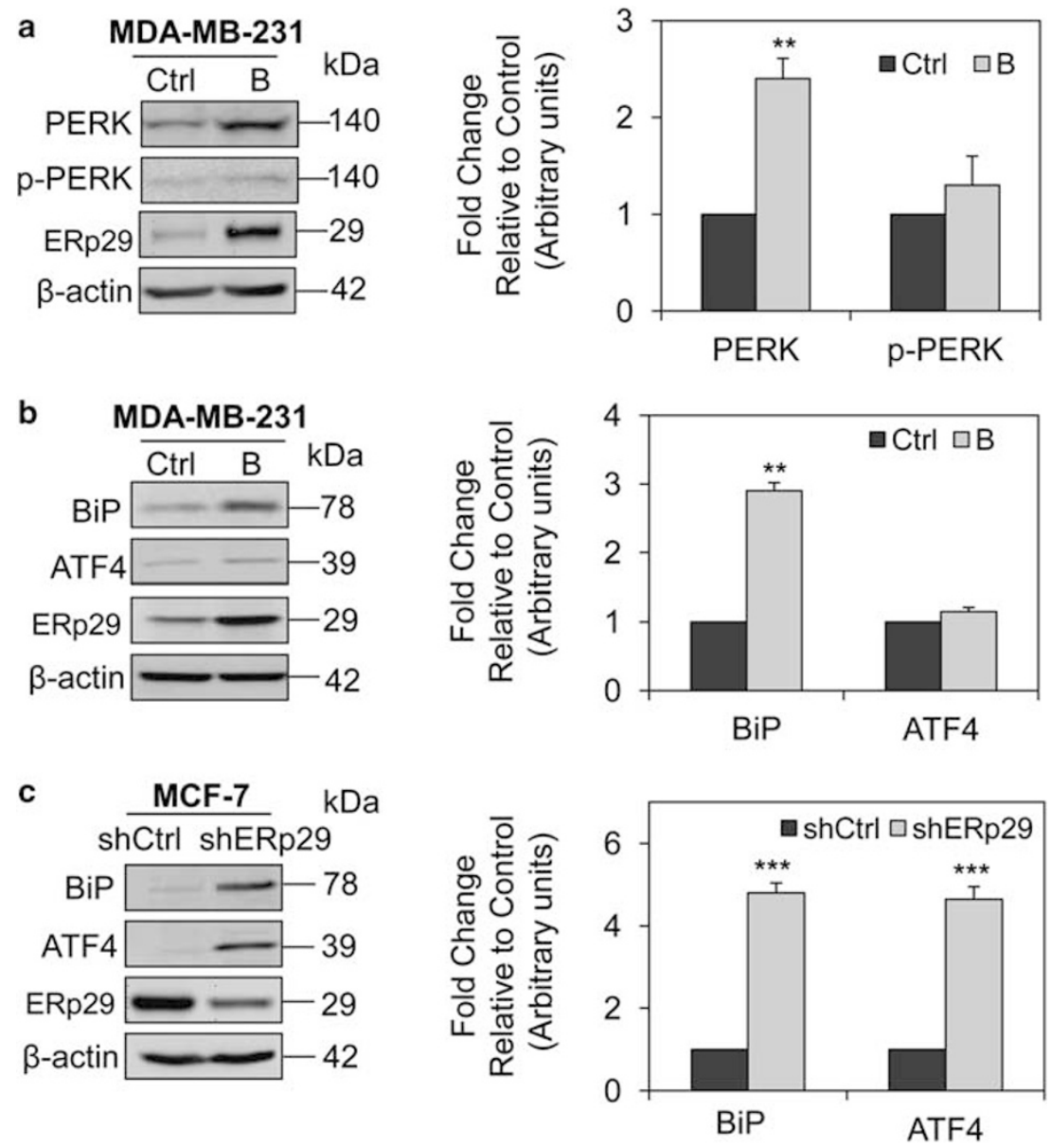

Figure 6 Effect of ERp29 on the expression of other ER stress molecules. (a) Effect of ERp29 on PERK expression and phosphorylation. Overexpression of ERp29 in MDA-MB-231 cells upregulates PERK expression, but does not affect phosphorylated PERK ( $p$-PERK) relative to these cells transfected with the empty vector alone. (b) Effect of ERp29 overexpression in MDA-MB-231 cells significantly upregulates the ER stress molecule, BiP, but has little effect on ATF4 expression. (c) BiP expression is also significantly increased in MCF-7 cells transfected with shERp29 relative to cells transfected with the scrambled shRNA control. ATF4 expression is increased in ERp29-knockdown MCF-7 cells relative to these cells transfected with the scrambled shRNA control, implicating an activation of p-eIF2 $\alpha$ downstream signaling by decreased ERp29 expression. Data represent the fold change in expression after normalization to $\beta$-actin, compared with control cells. Results are mean \pm s.d. (three experiments). ${ }^{* *} P<0.01,{ }^{* * *} P<0.001$. 
expressing MDA-MB-231 cells (clone B) compared with empty vector-transfected control cells. The fact that increased PERK was not further phosphorylated could be due to the increased level of $\mathrm{p} 58^{\mathrm{IPK}}$, which binds to PERK and represses its phosphorylation. ${ }^{37}$

Overexpression of ERp29 significantly $(P<0.05)$ increased the expression of another ER-stress related molecule, namely BiP, by 2.9 -fold in ERp29-overexpressing MDA-MB-231 cells (Figure 6b). However, paradoxically, knockdown of ERp29 in MCF-7 cells (using shERp29) also resulted in a significant increase $(P<0.001)$ of $\mathrm{BiP}$ expression (Figure $6 \mathrm{c})$. Hence, there may not be a direct mechanistic link between these two ER stress-related molecules.

Furthermore, expression of the eIF $2 \alpha$ phosphorylationdependent transcription factor, ATF $4,{ }^{37}$ was not markedly changed in ERp29-overexpressing MDA-MB-231 cells relative to empty vector-transfected control cells (Figure 6b). This is probably because the relative phosphorylation of eIF $2 \alpha$ was not significantly altered by ERp29 overexpression in MDAMB-231 cells (Figure 4a; see densitometric analysis). However, consistent with enhanced eIF $2 \alpha$ phosphorylation in
ERp29-knockdown MCF-7 cells (Figure 4a; right immunoblot panel), knockdown of ERp29 in MCF-7 cells significantly $(P<0.001)$ increased the expression of ATF4 (Figure 6c). Collectively, these results indicate that ER-dependent pro-apoptotic signaling is markedly suppressed by ERp29 in these slowly proliferating cells.

\section{Silencing of $p 58^{\text {IPK }}$ Activates the p-elF2 $\alpha / A T F 4 / C H O P$ Pathway in ERp29-Overexpressing MDA-MB-231 Cells}

The above data demonstrate that overexpression of ERp29 upregulates $\mathrm{p} 58^{\mathrm{IPK}}$, leading to inhibition of eIF $2 \alpha$ phosphorylation. Given that silencing of $\mathrm{p} 58^{\mathrm{IPK}}$ in ERp29-overexpressing MDA-MB-231 cells reactivates phosphorylation of eIF $2 \alpha$ (Figure $5 c$, left immunoblot panel), the reduction of p $58^{\mathrm{IPK}}$ expression may be responsible for the activation of the eIF2 $\alpha$ phosphorylation-dependent ATF4/CHOP pro-apoptotic pathway. In fact, silencing of $\mathrm{p} 58^{\mathrm{IPK}}$ in ERp29-overexpressing MDA-MB-231 cells (clone B) led to a significant $(P<0.01)$ increase of both ATF4 and CHOP expression (Figure 7a; left immunoblot panel). Similar results were also achieved in MCF-7 cells in which silencing of $\mathrm{p} 58^{\mathrm{IPK}}$
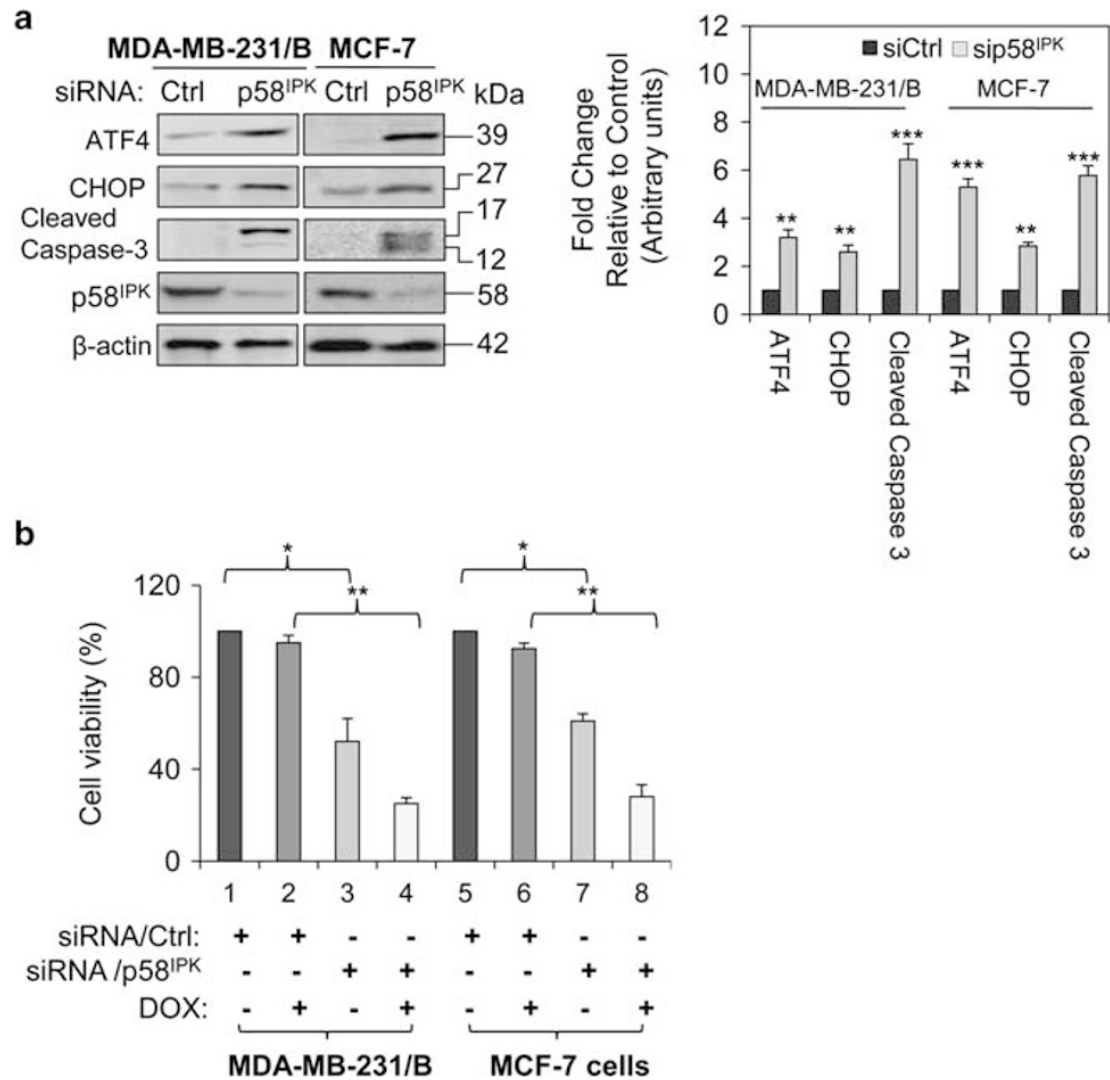

Figure 7 Silencing of $\mathrm{p} 58^{\mathrm{IPK}}$ activates the elF2 $\alpha$ phosphorylation-dependent ATF4/CHOP pro-apoptotic pathway and increases doxorubicin-induced cell apoptosis. (a) Silencing of p58 ${ }^{\mathrm{PR}}$ activates the ATF4/CHOP pathway and increases expression of cleaved caspase-3. ERp29-overexpressing MDA-MB-231 cells or MCF-7 cells were treated with p58 ${ }^{\mathrm{IPK}}$ siRNA or scrambled siRNA for $24 \mathrm{~h} / 37^{\circ} \mathrm{C}$ as described in Figure 5 and the indicated protein expression was analyzed by western blot. Silencing of $\mathrm{p} 58^{\mathrm{IPK}}$ stimulated the cleavage of caspase-3 $(12$ and $17 \mathrm{kDa})$ in p58 ${ }^{\mathrm{IPK}}$ siRNA-treated cells. (b) Silencing of p58 $8^{\mathrm{IPK}}$ sensitizes both ERp29-overexpressing MDA-MB-231 cells and MCF-7 cells to the cytotoxic drug, doxorubicin (DOX). Cells were incubated with p58 $8^{\mathrm{PK}}$ siRNA or scrambled siRNA for $24 \mathrm{~h} / 37^{\circ} \mathrm{C}$, followed by treatment with DOX ( $200 \mathrm{nM}$ ) or control medium for $24 \mathrm{~h} / 37^{\circ} \mathrm{C}$. Cell viability was assessed using MTS as described in the 'Materials and methods'. As indicated, $\mathrm{p} 58^{\mathrm{IPK}}$ silencing together with DOX synergistically increased cell death in both cell types. Data are mean \pm s.d. (three experiments). ${ }^{\star} P<0.05,{ }^{* *} P<0.01,{ }^{* * * P}<0.001$. 
markedly and significantly $(P<0.01-0.001)$ increased the expression of ATF4 and CHOP by 5.1- and 2.9-fold, respectively (Figure 7a; right immunoblot panel). In agreement with previous studies showing that $\mathrm{p} 58^{\mathrm{IPK}}$ overexpression decreased eIF2 $\alpha$ phosphorylation-dependent expression of ATF $4 / C H O P,{ }^{37}$ our data further demonstrate that $\mathrm{p} 58^{\mathrm{IPK}}$ is a key regulator of the p-eIF2 $\alpha /$ ATF4/CHOP pathway. Moreover, upregulation of $\mathrm{p} 58^{\mathrm{IPK}}$ seems crucial in maintaining ERp29-induced cell survival.

\section{Silencing of $\mathrm{p} 58^{\mathrm{IPK}}$ Sensitizes Doxorubicin and Induces Cell Death}

Our previous studies have shown that overexpression of ERp29 in MDA-MB-231 cells markedly increased its resistance to doxorubicin, whereas knockdown of ERp29 in MCF-7 cells sensitized them to this agent. ${ }^{9}$ Furthermore, the above data demonstrate an important role of $\mathrm{p} 58^{\mathrm{IPK}}$ in inhibiting eIF2 $\alpha$ phosphorylation and pro-apoptotic signaling in these ERp29-overexpressing cells. Therefore, we examined whether upregulation of $\mathrm{p} 58^{\mathrm{IPK}}$ modulates ERp29-mediated cell survival and drug resistance.

To determine whether silencing of $\mathrm{p} 58^{\mathrm{IPK}}$ results in sensitivity to doxorubicin and causes cell death, ERp29-overexpressing MDA-MB-231 cells (clone B) and also MCF-7 cells were treated with $\mathrm{p} 58^{\mathrm{IPK}}$ siRNA or scrambled control siRNA for $24 \mathrm{~h} / 37^{\circ} \mathrm{C}$, followed by a $24 \mathrm{~h} / 37^{\circ} \mathrm{C}$ treatment with doxorubicin $(200 \mathrm{nM})$. The viability of these cells was then examined. As indicated in Figure 7a, ERp29-overexpressing MDA-MB-231 cells (clone B; left immunoblot panel) and MCF-7 cells (right immunoblot panel) treated with $\mathrm{p} 58^{\mathrm{IPK}}$ siRNA showed enhanced expression of ATF4, CHOP and cleaved caspase-3, indicating activation of apoptosis after p5 $8^{\mathrm{IPK}}$ silencing.

Further studies showed that these $\mathrm{p} 58^{\mathrm{IPK}}$ siRNA-treated cells had markedly decreased cell viability than did cells treated with scrambled control siRNA $(P<0.05$; Figure $7 \mathrm{~b}$, column 3 vs 1 and column 7 vs 5). Hence, these results are consistent with the conclusion that the reduced levels of $\mathrm{p} 58^{\mathrm{IPK}}$ leads to increased apoptosis and cell death potentially through the ATF4/CHOP pro-apoptotic pathway. When these control and p58 $8^{\mathrm{IPK}}$ siRNA-treated cells were incubated with doxorubicin, ERp29-overexpressing MDA-MB-231 cells pre-treated with $\mathrm{p} 58^{\mathrm{IPK}}$ siRNA showed a significant $(P<0.01) 3.2$-fold reduction of cell viability in these slowly proliferating cells pre-treated with control siRNA (column 4 $v s$ 2). These results suggested that silencing $\mathrm{p} 58^{\mathrm{IPK}}$ significantly sensitizes these ERp29-transfected cells to this drug. A similar effect was also observed using MCF-7 cells, in which repression of $\mathrm{p} 58^{\mathrm{IPK}}$ significantly $(P<0.01)$ enhanced the cytotoxicity of doxorubicin, leading to an $\sim 2.5$-fold decrease in cell viability compared with cells pre-treated with scrambled control siRNA (Figure 7b, column 8 vs 6). Collectively, these results showed that silencing of $\mathrm{p} 58^{\mathrm{IPK}}$ in MCF-7 cells and ERp29-overexpressing MDA-MB-231 cells re-sensitizes them to doxorubicin by activating ATF4/CHOP/ caspase-3 pro-apoptotic signaling.

\section{DISCUSSION}

We previously reported that overexpression of ERp29 induced $G_{0} / G_{1}$ arrest and inhibited tumorigenesis in breast MDA-MB-231 cancer cells. ${ }^{6}$ In this study, we demonstrate a novel molecular mechanism underlying ERp29-induced cell growth arrest and survival.

In the slowly proliferating ERp29-overexpressing MDA-MB-231 cell model, increased ERp29 levels significantly reduced the expression of uPAR, $\beta_{1}$-integrin and EGFR, which are essential players in the decision between tumor cell proliferation and growth arrest ${ }^{12}$ (Figure 1). The reduction of this complex leads to attenuation of FAK/p-ERK and activation of $\mathrm{p} 38$ that consequently propels proliferative tumor cells into a slowly proliferating or quiescent state by downregulating basal eIF2 $\alpha$ expression, reducing cyclin $\mathrm{D}_{2}$ and increasing p15 and p21 levels. Importantly, we demonstrated that upregulation of $\mathrm{p} 58^{\mathrm{IPK}}$ in ERp29 overexpressing cells has a critical role in attenuating eIF $2 \alpha$ phosphorylation and inhibiting the ATF4/CHOP/caspase-3 pro-apoptotic pathway, leading to enhanced cell survival.

The role of the uPAR- $\beta_{1}$-integrin-EGFR complex and its downstream molecules (eg, FAK and p38) in modulating tumor cell dormancy has been well described in dormant squamous tumor cell models. ${ }^{10,15,16,32}$ The current studies using breast cancer cells further support the significance of the loss of the uPAR- $\beta_{1}$-integrin-EGFR complex in inhibiting tumor cell proliferation by activating p38 phosphorylation and downregulating FAK. Phosphorylation of p38 due to the loss of this complex has been demonstrated to be a central regulator of cell dormancy, survival and apoptosis. $^{14,39}$

A significant link of p38 phosphorylation with cell-cycle arrest at the $G_{0} / G_{1}$ phase and cell survival through ER stress was established by the fact that activation of p38 enhanced PERK/p-eIF $2 \alpha$ signaling by stimulating phosphorylation of eIF $2 \alpha,{ }^{24}$ leading to the induction of $G_{0} / G_{1}$ arrest by downregulating cyclin $\mathrm{D}_{1}{ }^{22,23}$ Interestingly, in our established ERp29-overexpression MDA-MB-231 cell model, ${ }^{6}$ the expression of basal eIF2 $\alpha$ was highly inhibited (Figure $4 \mathrm{a}$, left immunoblot) without affecting its overall relative phosphorylation (see densitometry, Figure 4a). In addition, the expression of cyclin $\mathrm{D}_{2}$, was significantly decreased and the cyclin-dependent kinase inhibitors, p15 and p21, were markedly increased by ERp29 overexpression (Figure 3a). These data suggest a novel mechanism of ERp29 in driving proliferating cells into $G_{0} / G_{1}$ arrest. $^{6}$

In this study, we also demonstrate a critical role of $\mathrm{p} 38$ phosphorylation in the ERp29-mediated inhibition of cell growth that was demonstrated by a $G_{0} / G_{1}$ arrest in our previous investigation. ${ }^{6}$ This is reflected by the fact that inhibition of p-p38 kinase activity by the pharmacological inhibitor, SB203580, in ERp29-overexpressing MDA-MB-231 
cells increased the expression of cyclin $\mathrm{D}_{2}$ and decreased the expression of p15 (Figure 3c). At the same time, inhibition of p-p38 kinase increased the level of basal eIF $2 \alpha$ (Figure $4 \mathrm{~b}$, left immunoblot panel), indicating the importance of p38 phosphorylation in negatively regulating basal eIF2 $\alpha$ expression in these cell models.

c-JUN/AP-1 is one of the transcription factors regulating eIF2 $\alpha$ expression. ${ }^{40}$ Previous studies examining transcription factor profile analysis revealed that c-JUN/AP-1 is negatively regulated by $\mathrm{p} 38$ phosphorylation. ${ }^{24,41}$ In fact, it was found to be reduced in dormant D-HEp3 cells ${ }^{25}$ and also in the ERp29-overexpressing MDA-MB-231 cell model. ${ }^{6}$ The ERp29-mediated downregulation of basal eIF2 $\alpha$ could be due to the inhibition of c-JUN by activation of p38. Collectively, our investigation demonstrates the ERp29-mediated activation of p38 negatively regulates basal eIF $2 \alpha$ expression.

ER stress signaling is an important determinant in deciding cell dormancy, survival and autophagy. ${ }^{18,21,42}$ We showed that overexpression of ERp29 in MDA-MB-231 cells leads to activation of ER stress by stimulating splicing of the transcription factor, XBP-1. ${ }^{9}$ Enhanced phosphorylation of eIF2 $\alpha$ is a mechanism leading to attenuation of general protein synthesis and activation of ATF4/CHOP under ER stress. ${ }^{43}$ However, our results showed that overexpression of ERp29 is unable to increase eIF2 $\alpha$ phosphorylation ${ }^{9}$ (Figure 4a; left immunoblot panel), although p-p38 levels are markedly increased in these cells (Figure 2b). Similarly, phosphorylation of PERK, one of the specific kinases that phosphorylate eIF $2 \alpha{ }^{23}$ is not significantly altered, although its basal expression is increased (Figure 6a) in ERp29-overexpressing MDA-MB-231 cells. In these cell models, the ERp29-induced activation of p38 is unable to activate the p-PERK/p-eIF2 $\alpha$ pathway. This may implicate that phosphorylation of PERK and its downstream eIF $2 \alpha$ is concomitantly inhibited by other molecules, which counteract the phosphorylation exerted by its upstream kinases (eg, p-p38).

Considering this idea, we hypothesized the involvement of $\mathrm{p} 58^{\mathrm{IPK}}$, which is a downstream effector of XBP-1 activation. ${ }^{36}$ Indeed, in this study, we showed that $\mathrm{p} 58^{\mathrm{IPK}}$ was significantly upregulated in ERp29-overexpressing MDA-MB-231 cells. $\mathrm{p} 58^{\mathrm{IPK}}$ was originally identified as an inhibitor of PKR, which inhibits PKR function in eIF $2 \alpha$ phosphorylation. ${ }^{44,45}$ Recent studies have further demonstrated that $\mathrm{p} 58^{\mathrm{IPK}}$ can interact with and inhibit PERK phosphorylation, leading to decreased phosphorylation of eIF $2 \alpha{ }^{46}$ In our cell models, silencing of p $58^{\mathrm{IPK}}$ stimulated eIF $2 \alpha$ phosphorylation and activated the expression of ATF $4 / \mathrm{CHOP}$ and also the cleavage of caspase- 3 (Figure 7a, left immunoblot panel). This is further supported by earlier studies showing eIF $2 \alpha$ phosphorylation-mediated, stress-induced apoptosis. ${ }^{47}$ Therefore, upregulation of $\mathrm{p} 58^{\mathrm{IPK}}$ may facilitate cell survival under stress in ERp29-overexpressing MDA-MB-231 cells by repressing eIF2 $\alpha$ phosphorylation.

It is well known that GADD34, a downstream target of activated $\mathrm{p}$-eIF $2 \alpha$, also inhibits eIF $2 \alpha$ phosphorylation by a feedback loop. ${ }^{48}$ Nevertheless, it should be noted that induction of $\mathrm{p} 58^{\mathrm{IPK}}$ is directly regulated by ATF6 or the IRE1/ XBP-1-mediated arm of the UPR and is an upstream molecule that can directly bind to PERK to inactivate PERK/peIF $2{ }^{36,49}$ Our studies showed that induction of $\mathrm{p} 58^{\mathrm{IPK}}$ by ERp29 may help to protect these slowly proliferating cells from p-p38-activated excessive ER stress by de-phosphorylating eIF $2 \alpha$. As such, disturbing the signaling balance of p-p38-activated p-PERK/p-eIF2 $\alpha$ and p58 ${ }^{\mathrm{IPK}}$-repressed p-PERK/p-eIF $2 \alpha$ at the steady state could impair ERp29-induced growth arrest in MDA-MB-231 cells. As demonstrated, activation of the p-eIF2 $\alpha /$ ATF $4 / C H O P$ pro-apoptotic pathway by silencing $\mathrm{p} 58^{\mathrm{IPK}}$ led to increased sensitivity of these slowly proliferating cells to doxorubicin treatment (Figure $7 \mathrm{~b}$ ). Hence, our data indicate that $\mathrm{p} 58^{\mathrm{IPK}}$ is an important coordinator in modulating the crosstalk between ERp29mediated ER stress and ER-dependent pro-apoptotic signaling by inhibiting eIF2 $\alpha$ phosphorylation in ERp29overexpressing MDA-MB-231 cells.

Breast tumor cell dormancy is a significant clinical problem in cancer treatment. Most dormant cells do not express proliferative markers and are resistant to conventional therapies (eg, doxorubicin) that target actively dividing cells. ${ }^{50}$ In general, dormant cells are characterized by a cellcycle $G_{0} / G_{1}$ arrest and/or by similar proliferative and apoptotic rates, leading to no overall gain in tumor mass. ${ }^{10}$ The fact that overexpression of ERp29 in high proliferative MDAMB-231 cells resulted in $G_{0} / G_{1}$ arrest ${ }^{6}$ and resistance to doxorubicin ${ }^{9}$ suggests a potential role of ERp29 in inducing cellular dormancy. This hypothesis will be assessed in the future using the established in vitro three-dimensional cell culture system ${ }^{31}$ and in vivo animal models ${ }^{16}$. Given the limited clinical accessibility to dormant tumors, establishing in vitro suitable experimental models is critical in understanding the mechanisms involved in tumor cell dormancy and distant metastasis and in developing new therapeutic strategies for the treatment of dormant cancer.

In summary, we demonstrate the molecular mechanisms underlying ERp29-induced breast cancer cell growth arrest and survival. As illustrated in Figure 8, overexpression of ERp29 downregulates the expression of uPAR- $\beta_{1}$-integrinEGFR and subsequently activates p38 phosphorylation. Activation of p38 inhibits basal eIF2 $\alpha$ expression, reduces cyclin $\mathrm{D}_{2}$ and increases p15 and p21 levels, leading to cellcycle $G_{0} / G_{1}$ arrest. On the other hand, upregulation of $\mathrm{p} 58^{\mathrm{IPK}}$ in ERp29-overexpressing cells suppresses the activation of p-p38/p-PERK/p-eIF2 $\alpha$ by repressing eIF $2 \alpha$ phosphorylation. Thus, this prevents these slowly proliferating cells from undergoing ER-dependent apoptosis driven by activation of the ATF4/CHOP/caspase-3 pathway. Consequently, the interplay between $\mathrm{p} 38$ phosphorylation and $\mathrm{p} 58^{\mathrm{IPK}}$ upregulation has key roles in modulating ERp29-induced cell growth arrest and survival. This new knowledge could lead to novel and effective therapies against slowly proliferating and drugresistant cancer cells, eg, by targeting $\mathrm{p} 58^{\mathrm{IPK}}$. 


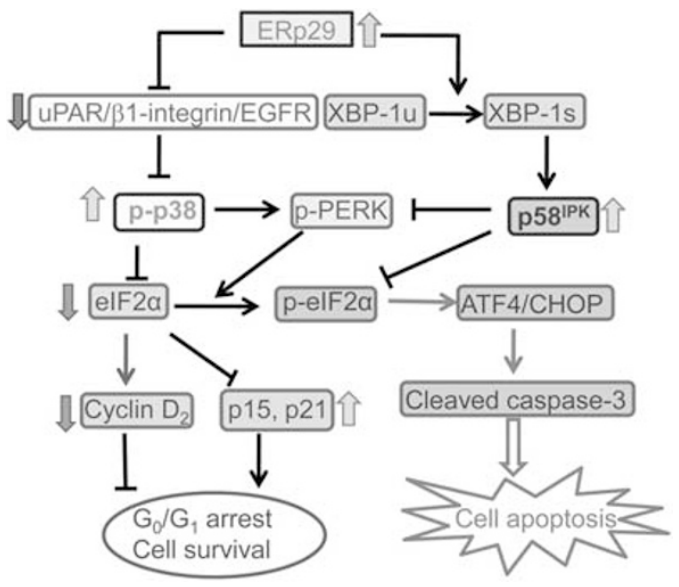

Figure 8 Molecular mechanism of ERp29-induced cancer cell growth arrest and survival. Overexpression of ERp29 in MDA-MB-231 cells decreases expression of the UPAR- $\beta 1$-integrin-EGFR ternary complex, leading to activation of p38. Phosphorylation of p38 inhibits the expression of basal elF $2 \alpha$ and cyclin $D_{2}$ and increases the expression of $p 15$ and p21, thus causing the $\mathrm{G}_{\mathrm{o}} / \mathrm{G}_{1}$ arrest observed in our previous study. ${ }^{6}$ On the other hand, overexpression of ERp29 upregulates $\mathrm{p} 58^{\mathrm{IPK}}$ by enhancing XBP-1 splicing. The upregulated $\mathrm{p} 58^{\mathrm{IPK}}$ functionally counteracts the upstream kinases of elF $2 \alpha$ to inhibit elF $2 \alpha$ phosphorylation and attenuates activation of the p-PERK/p-elF $2 \alpha$ pathway. Reduction of $p 58^{\mathrm{IPK}}$ by siRNA leads to activation of the elF $2 \alpha$ phosphorylation-dependent ATF4/CHOP/cleaved caspase-3 pathway and cell apoptosis/sensitivity to doxorubicin. Hence, the interplay between the activation of $\mathrm{p} 38$ and upregulation of $\mathrm{p} 58^{\mathrm{IPK}}$ is a critical event for maintaining ERp29-induced growth arrest and survival.

\section{ACKNOWLEDGEMENTS}

We thank Ms Songci Xu from the Department of Pathology for her assistance in this work. This work was supported by the research grant awarded to DZ from the Agency of Science, Technology and ResearchBiomedical Research Council (A-STAR-BMRC 07/1/21/19/496). DRR thanks the National Health and Medical Research Council of Australia for Project Grants and a Senior Principal Research Fellowship.

\section{DISCLOSURE/CONFLICT OF INTEREST}

The authors declare no conflict of interest.

1. Ellgaard L, Ruddock LW. The human protein disulphide isomerase family: substrate interaction and function properties. EMBO Rep 2005;8:28-32.

2. Mkrtchian S, Sandalova T. ERp29, an unusual redox-inactive member of the thioredoxin family. Antioxid Redox Signal 2006;8:325-337.

3. Rainey-Barger EK, Mkrtchian S, Tsai B. The C-terminal domain of ERp29 mediates polyomavirus binding, unfolding, and infection. J Virol 2009;83:1483-1491.

4. Rainey-Barger EK, Mkrtchian S, Tsai B. Dimerization of ERp29, a PDI-like protein, is essential for its diverse functions. Mol Biol Cell 2007;18:1253-1260.

5. Das S, Smith TD, Sarma JD, et al. ERp29 restricts connexin43 oligomerization in the endoplasmic reticulum. Mol Biol Cell 2009;20:2593-2604.

6. Bambang IF, Xu S, Zhou J, et al. Overexpression of endoplasmic reticulum protein 29 regulates mesenchymal-epithelial transition and suppresses xenograft tumor growth of invasive breast cancer cells. Lab Invest 2009;89:1229-1242.

7. Qi L, Wu P, Zhang $X$, et al. Inhibiting ERp29 expression enhances radiosensitivity in human nasopharyngeal carcinoma cell lines. Med Oncol 2011; advance online publication, 11 April 2011; doi: 10.1007/ s12032-011-9929-5.

8. Farmaki E, Mkrtchian S, Papazian I, et al. ERp29 regulates response to doxorubicin by a PERK-mediated mechanism. Biochim Biophys Acta 2011;1813:1165-1171.
9. Zhang D, Putti TC. Over-expression of ERp29 attenuates doxorubicininduced cell apoptosis through up-regulation of Hsp27 in breast cancer cells. Exp Cell Res 2010;316:3522-3531.

10. Yu W, Kim J, Ossowski L. Reduction in surface urokinase receptor forces malignant cells into a protracted state of dormancy. J Cell Biol 1997;137:767-777.

11. Ranganathan AC, Adam AP, Aguirre-Ghiso JA. Opposing roles of mitogenic and stress signaling pathways in the induction of cancer dormancy. Cell Cycle 2006;5:1799-1807.

12. Allgayer $\mathrm{H}$, Aguirre-Ghiso JA. The urokinase receptor (u-PAR)-a link between tumor cell dormancy and minimal residual disease in bone marrow? APMIS 2008;116:602-614.

13. Aguirre-Ghiso JA, Estrada $Y$, Liu D, et al. ERK(MAPK) activity as a determinant of tumor growth and dormancy; regulation by p38(SAPK). Cancer Res 2003;63:1684-1958.

14. Aguirre-Ghiso JA. Models, mechanisms and clinical evidence for cancer dormancy. Nat Rev Cancer 2007;7:834-846.

15. Aguirre Ghiso JA, Kovalski K, Ossowski L. Tumor dormancy induced by downregulation of urokinase receptor in human carcinoma involves integrin and MAPK signaling. J Cell Biol 1999;147:89-104.

16. Aguirre-Ghiso JA, Liu D, Mignatti $A$, et al. Urokinase receptor and fibronectin regulate the ERK(MAPK) to p38(MAPK) activity ratios that determine carcinoma cell proliferation or dormancy in vivo. Mol Biol Cell 2001;12:863-879.

17. Schewe DM, Aguirre-Ghiso JA. ATF6alpha-Rheb-mTOR signaling promotes survival of dormant tumor cells in vivo. Proc Natl Acad Sci USA 2008;105:10519-10524.

18. Ranganathan AC, Adam AP, Zhang $L$, et al. Tumor cell dormancy induced by P38SAPK and ER-stress signaling: an adaptive advantage for metastatic cells? Cancer Biol Ther 2006;5:729-735.

19. Welihinda AA, Tirasophon W, Kaufman RJ. The cellular response to protein misfolding in the endoplasmic reticulum. Gene Exp 1999;7:293-300.

20. Ron D, Walter P. Signal integration in the endoplasmic reticulum unfolded protein response. Nat Rev Mol Cell Biol 2007;8:519-529.

21. Wang G, Yang ZQ, Zhang K. Endoplasmic reticulum stress response in cancer: molecular mechanism and therapeutic potential. Am J Transl Res 2010;2:65-74.

22. Rutkowski DT, Kaufman RJ. A trip to the ER: coping with stress. Trends Cell Biol 2004;14:20-28.

23. Brewer JW, Diehl JA. PERK mediates cell-cycle exit during the mammalian unfolded protein response. Proc Natl Acad Sci USA 2000;97:12625-12630.

24. Ranganathan $A C$, Zhang $L$, Adam AP, et al. Functional coupling of $p 38$ induced up-regulation of BiP and activation of RNA-dependent protein kinase-like endoplasmic reticulum kinase to drug resistance of dormant carcinoma cells. Cancer Res 2006;66:1702-1711.

25. Adam AP, George A, Schewe D, et al. Computational identification of a p38SAPK-regulated transcription factor network required for tumor cell quiescence. Cancer Res 2009;69:5664-5672.

26. Wong LL, Chang CF, Koay ES, et al. Tyrosine phosphorylation of PP2A is regulated by HER-2 signalling and correlates with breast cancer progression. Int J Oncol 2009;34:1291-1301.

27. Leber TM, Frances R, Balkwill FR. Zymography: a single-step staining method for quantitation of proteolytic activity on substrate gels. Anal Biochem 1997;249:24-28.

28. Ahmad A, Kong D, Wang Z, et al. Down-regulation of UPA and UPAR by $3,3^{\prime}$-diindolylmethane contributes to the inhibition of cell growth and migration of breast cancer cells. J Cell Biochem 2009;108:916-925.

29. Kunigal S, Lakka SS, Gondi CS, et al. RNAi-mediated downregulation of urokinase plasminogen activator receptor and matrix metalloprotease9 in human breast cancer cells results in decreased tumor invasion, angiogenesis and growth. Int J Cancer 2007;121:2307-2316.

30. Hsu T, Trojanowska M, Watson DK. Ets proteins in biological control and cancer. J Cell Biochem 2004;91:896-890.

31. Barkan $\mathrm{D}$, Kleinman $\mathrm{H}$, Simmons $\mathrm{JL}$, et al. Inhibition of metastatic outgrowth from single dormant tumor cells by targeting the cytoskeleton. Cancer Res 2008;68:6241-6250.

32. Aguirre Ghiso JA. Inhibition of FAK signaling activated by urokinase receptor induces dormancy in human carcinoma cells in vivo. Oncogene 2002;21:2513-2524.

33. Ahmed N, Oliva K, Wang $Y$, et al. Downregulation of urokinase plasminogen activator receptor expression inhibits Erk signalling with 
concomitant suppression of invasiveness due to loss of uPAR-beta1 integrin complex in colon cancer cells. Br J Cancer 2003;89:374-384.

34. Loesch M, Zhi HY, Hou SW, et al. p38gamma MAPK cooperates with cJun in trans-activating matrix metalloproteinase 9. J Biol Chem 2010;285:15149-15158.

35. Kim MS, Lee EJ, Kim HR, et al. p38 kinase is a key signaling molecule for $\mathrm{H}$-Ras-induced cell motility and invasive phenotype in human breast epithelial cells. Cancer Res 2003;63:5454-5461.

36. Lee AH, Iwakoshi NN, Glimcher LH. XBP-1 regulates a subset of endoplasmic reticulum resident chaperone genes in the unfolded protein response. Mol Cell Biol 2003;23:7448-7459.

37. van Huizen $\mathrm{R}$, Martindale $\mathrm{JL}$, Gorospe $\mathrm{M}$, et al. P58 $8^{\mathrm{IPK}}$, a novel endoplasmic reticulum stress-inducible protein and potential negative regulator of elF2alpha signaling. J Biol Chem 2003;278:15558-15564.

38. Harding HP, Novoa I, Zhang $Y$, et al. Regulated translation initiation controls stress-induced gene expression in mammalian cells. Mol Cell 2000;6:1099-1108.

39. Bulavin DV, Fornace Jr AJ. p38 MAP kinase's emerging role as a tumor suppressor. Adv Cancer Res 2004;92:95-118.

40. Ferreiro I, Joaquin $M$, Islam $A$, et al. Whole genome analysis of p38 SAPK-mediated gene expression upon stress. BMC Genomics 2010;11:144.

41. Hümbelin M, Safer B, Chiorini JA, et al. Isolation and characterization of the promoter and flanking regions of the gene encoding the human protein-synthesis-initiation factor 2 alpha. Gene 1989;81:315-324.

42. Verfaillie $T$, Salazar M, Velasco $G$, et al. Linking ER stress to autophagy: potential implications for cancer therapy. Int J Cell Biol 2010;2010:930509.
43. Harding $\mathrm{HP}$, Zhang $\mathrm{Y}$, Zeng $\mathrm{H}$, et al. An integrated stress response regulates amino acid metabolism and resistance to oxidative stress. Mol Cell 2003;11:619-633.

44. Lee TG, Tomita J, Hovanessian AG, et al. Characterization and regulation of the 58000 -dalton cellular inhibitor of the interferon-induced, dsRNA-activated protein kinase. J Biol Chem 1992;267:14238-14243.

45. Polyak SJ, Tang N, Wambach M, et al. The P58 cellular inhibitor complexes with the interferon-induced, double-stranded RNAdependent protein kinase, PKR, to regulate its autophosphorylation and activity. J Biol Chem 1996;271:1702-1707.

46. Yan W, Frank $\mathrm{CL}$, Korth MJ, et al. Control of PERK elF2alpha kinase activity by the endoplasmic reticulum stress-induced molecular chaperone P58 ${ }^{\mathrm{IPK}}$. Proc Natl Acad Sci USA 2002;99:15920-15925.

47. Srivastava SP, Kumar KU, Kaufman RJ. Phosphorylation of eukaryotic translation initiation factor 2 mediates apoptosis in response to activation of the double-stranded RNA-dependent protein kinase. J Biol Chem 1998;273:2416-2423.

48. Novoa I, Zeng H, Harding HP, et al. Feedback inhibition of the unfolded protein response by GADD34-mediated dephosphorylation of elF2alpha. J Cell Biol 2001;153:1011-1022.

49. Yoshida $\mathrm{H}$, Matsui $\mathrm{T}$, Yamamoto $\mathrm{A}$, et al. XBP1 mRNA is induced by ATF6 and spliced by IRE1 in response to ER stress to produce a highly active transcription factor. Cell 2001;107:881-891.

50. Naumov GN, Townson JL, MacDonald IC, et al. Ineffectiveness of doxorubicin treatment on solitary dormant mammary carcinoma cells or late-developing metastases. Breast Cancer Res Treat 2003;82:199-206. 